\title{
A study on the hemocompatibility of dendronized chitosan derivatives in red blood cells
}

This article was published in the following Dove Press journal:

Drug Design, Development and Therapy

14 May 2015

Number of times this article has been viewed

\author{
Yanfang Zhoul,* \\ Jiemei $\mathrm{Li}^{1, *}$ \\ Fang Lu' \\ Junjie Deng ${ }^{2}$ \\ Jiahua Zhang' \\ Peijie Fang' \\ Xinsheng Peng' \\ Shu-Feng Zhou ${ }^{3}$ \\ 'Guangdong Medical Universtity, \\ Dongguan, Guangdong, People's \\ Republic of China; ${ }^{2}$ Department of \\ Materials Science and Engineering, \\ Drexel University, Philadelphia, PA \\ USA; ${ }^{3}$ Department of Pharmaceutical \\ Sciences, College of Pharmacy, \\ University of South Florida, Tampa, \\ FL, USA \\ *These authors contributed equally \\ to this work
}

\begin{abstract}
Dendrimers are hyperbranched macromolecules with well-defined topological structures and multivalent functionalization sites, but they may cause cytotoxicity due to the presence of cationic charge. Recently, we have introduced alkyne-terminated poly(amidoamine) (PAMAM) dendrons of different generations $(\mathrm{G}=2,3)$ into chitosan to obtain dendronized chitosan derivatives [Cs- $g$-PAMAM $(\mathrm{G}=2,3)$ ], which exhibited a better water solubility and enhanced plasmid DNA transfection efficiency. In this study, we attempted to examine the impact of Cs$g$-PAMAM $(\mathrm{G}=2,3)$ at different concentrations $(25 \mu \mathrm{g} / \mathrm{mL}, 50 \mu \mathrm{g} / \mathrm{mL}$, and $100 \mu \mathrm{g} / \mathrm{mL})$ on the morphology, surface structure, and viability of rat red blood cells (RBCs). The results showed that treatment of RBCs with Cs-g-PAMAM $(\mathrm{G}=2,3)$ at $50 \mu \mathrm{g} / \mathrm{mL}$ and $100 \mu \mathrm{g} / \mathrm{mL}$ induced a slightly higher hemolysis than $\mathrm{Cs}$, and Cs- $g$-PAMAM $(\mathrm{G}=3)$ caused a slightly higher hemolysis than Cs- $g$-PAMAM $(\mathrm{G}=2)$, but all values were $<5.0 \%$. Optical microscopic and atomic force microscopic examinations indicated that Cs-g-PAMAM $(\mathrm{G}=2,3)$ caused slight RBC aggregation and lysis. Treatment of RBCs with $100 \mu \mathrm{g} / \mathrm{mL}$ Cs- $g$-PAMAM $(\mathrm{G}=3)$ induced echinocytic transformation, and RBCs displayed characteristic irregular contour due to the folding of the periphery. Drephanocyte-like RBCs were observed when treated with $100 \mu \mathrm{g} / \mathrm{mL}$ Cs- $g$-PAMAM $(\mathrm{G}=3)$. Erythrocytes underwent similar shape transition upon treatment with Cs- $g$-PAMAM $(\mathrm{G}=2)$ or Cs. The roughness values $(\mathrm{Rms})$ of RBCs incubated with Cs-g-PAMAM $(\mathrm{G}=2,3)$ were significantly larger than those for RBCs incubated with physiological saline $(P<0.01)$, but the Rms showed no difference for Cs and Cs-g-PAMAM $(\mathrm{G}=2,3)(P>0.05)$. Furthermore, Cs- $g$-PAMAM $(\mathrm{G}=2,3)$ exhibited a lower cytotoxicity in human kidney $293 \mathrm{~T}$ cells. These results indicate that $\mathrm{Cs}-\mathrm{g}$-PAMAM $(\mathrm{G}=2,3)$ are hemocompatible but may disturb membrane and lipid structures at higher concentrations. Further safety and biocompatibility evaluations are warranted for Cs-g-PAMAM. Our findings prove helpful for a better understanding of the advantages of combining PAMAM dendrimers and chitosan to design and develop new, safe, and effective drug delivery vehicles.
\end{abstract}

Keywords: dendronized chitosan derivative, PAMAM, RBC, hemolysis, hemocompatibility

\section{Introduction}

Chitosan (Cs), a naturally occurring cationic mucopolysaccharide composed of $\beta$-(1-4)-linked 2-amino-2-deoxy- $\beta$-D-glucose and the $N$-acetylated analog, has been widely used in nonviral drug and gene delivery owing to good biocompatibility and biodegradability. ${ }^{1-4}$ However, Cs shows poor water solubility and low transfection efficiency. In recent years, a number of new Cs derivatives with improved transfection efficiency and better water solubility have been synthesized and characterized for drug and gene delivery. For example, urocanic acid-modified, ${ }^{5}$ hydrophobized, ${ }^{6,7}$ glycosylated, ${ }^{8}$ polyethylene glycol-modified (PEGylated), ${ }^{9,10}$ trimethylated, ${ }^{11,12}$ poly(amidoamine) (PAMAM) grafted, ${ }^{13,14}$ poly(epsilon-caprolactone) grafted, ${ }^{15,16}$ oligoamine grafted, ${ }^{17}$ and glycol grafted $\mathrm{Cs}^{18,19}$ have been characterized using in vitro 
and in vivo models. These modified Cs derivatives have distinct advantages and disadvantages when used as the drug and gene delivery systems or theranostics.

Dendrimers are monodisperse, artificial polymers, and hyperbranched macromolecules with well-defined topological structures and multivalent functionalization sites. ${ }^{20-23}$ They present important advantages over conventional linear or branched polymers, including monodispersity or low polydispersity, controlled size in the range of nanometers, controlled number of surface groups, and extremely high area/volume ratio. These unique characteristics render dendrimers amenable to serve as scaffolds and vehicles for nucleic acid and drug delivery and as the platform for theranostics. ${ }^{24,25}$ Only intermediate-generation $(\mathrm{G}=3.5-5)$ dendrimers are suitable as nanocarriers, with structures open enough to enable the loading and subsequent release of drug/gene molecules in a controllable manner. In the past years, cationic PAMAM dendrimers have been reported to improve the solubility of low-aqueous-soluble drugs and condense plasmid DNA or small interfering RNA and demonstrated successful delivery of DNA into the target cells. ${ }^{26-35}$ However, PAMAM dendrimers bearing amino terminals could cause certain cytotoxicity toward epithelial cells, endothelial cells, neurons, leukocytes, platelets, and red blood cells (RBCs). ${ }^{13,34,36-38}$ In particular, the RBC toxicity of PAMAM dendrimers has attracted attention due to safety concerns regarding hemolysis. Therefore, novel PAMAM-based dendrimers with low cytotoxicity and acceptable biocompatibility should be developed and characterized.

In our previous study, ${ }^{39}$ we reported that the chemical combination of PAMAM with $\mathrm{Cs}$ to generate PAMAM dendron-grafted Cs [Cs- $g$-PAMAM $(\mathrm{G}=2,3)]$, which exhibited a low cytotoxicity, strong binding ability to plasmid DNA, and enhanced transfection efficiency in both human kidney 293T and human nasopharyngeal carcinoma CNE2 cell lines. It is well known that RBCs comprise one of the most important components in the body's circulation system to deliver oxygen. To supply oxygen to the brain and other important organs, RBCs must deform as they pass through the narrow pores of capillaries. Beside their primary role of oxygen transport, RBC suspensions tend to aggregate under low-flow conditions or at stasis. Furthermore, numerous signaling molecules, signaling cascades/pathways, and networks have been discovered in $\mathrm{RBCs} .{ }^{40} \mathrm{RBCs}$ also bind to most drugs and nucleic acids and carry them everywhere in the body. ${ }^{41-43}$ Considering RBCs' main advantages, including biocompatibility, biodegradability, immunocompatibility, simple and well-known structure and physiology, availability for sampling, and versatility in loading and use, erythrocytes are becoming one of the most promising drug delivery systems. ${ }^{41-43}$ Application of erythrocytes as containers for various drugs can both minimize the risk of side effects and pathologic immune responses against encapsulated agents as well as improve their therapeutic efficacy. ${ }^{41,44,45}$ On the other hand, the damage to the RBCs by drugs and nanocarriers may lead to serious problems such as hemolysis, anemia, liver and kidney injury, etc. Ruptured RBCs may alter the distribution of the drug and nanocarrier and thus change their biological responses. Because dendrimer-based nanocarrier systems can often enter the blood circulation and interact with blood cells including leukocytes and RBCs, the dendrimer's blood toxicity and biological properties should be carefully examined before systemic administration. In this study, we have investigated the impact of Cs-g-PAMAM with different dendron generations $(\mathrm{G}=2,3)$ on rat $\mathrm{RBC}$ morphology and hemolysis.

\section{Materials and methods Chemicals and reagents}

$\mathrm{Cs}$ (molecular weight $=10 \mathrm{kDa}$, deacetylation degree $=$ 85.3\%) was purchased from Jinan Haidebei Marine Bioengineering Co Ltd (Jinan, Shandong, People's Republic of China). Dendronized Cs derivatives (Cs-g-PAMAM) with different dendron generations $(\mathrm{G}=2,3)$ were synthesized as described in our previous study (Figure 1). ${ }^{39}$ PAMAM substitution degree of $\mathrm{Cs}$ - $g$-PAMAM $(\mathrm{G}=2)$ and $\mathrm{Cs}$ - $g$-PAMAM $(\mathrm{G}=3)$ was 25.1 and 23.3, respectively. Dulbecco's Modified Eagle's Medium (DMEM) was obtained from Corning Cellgro Inc (Herndon, VA, USA). Methyl thiazolyl tetrazolium (MTT) and dimethyl sulfoxide (DMSO) were purchased from Sigma-Aldrich Inc. (St Louis, MO, USA). Sodium chloride for injection $(0.9 \%, \mathrm{w} / \mathrm{v})$ was purchased from a local pharmacy. All other reagents were of analytical grade.

\section{Preparation of rat RBCs}

Blood was obtained from healthy Sprague-Dawley rats and was anticoagnlated with heparin sodium. Erythrocytes were separated from blood plasma by centrifugation at $1,500 \times g$ for 5 minutes at $4{ }^{\circ} \mathrm{C}$, then washed three times with physiological saline, and finally suspended in physiological saline to obtain a 2\% RBC suspension (v/v). Erythrocytes were used immediately after isolation. Animal experiments were carried out according to the protocol approved by the Experimental Animal Committee of Guangdong Medical Universtity, Dongguan, Guangdong, People's Republic of China. 


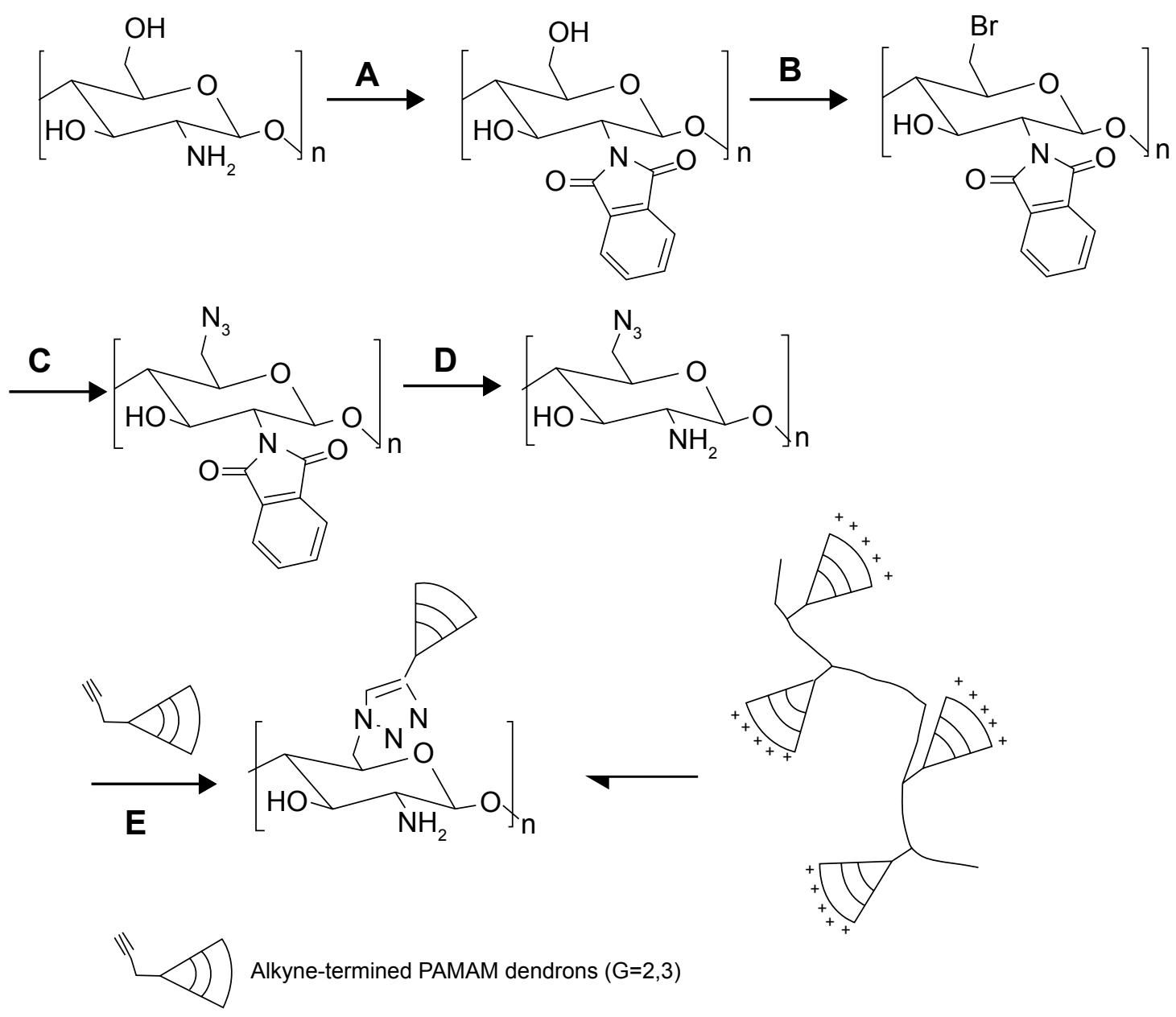

Figure I Synthesis scheme for PAMAM dendron-grafted Cs [Cs-g-PAMAM $(G=2,3)]$.

Notes: (A) Reaction in the presence of phthalic anhydride and dimethylformamide at $120^{\circ} \mathrm{C}$ for 8 hours; (B) reaction in the presence of $\mathrm{N}$-bromosuccinimide, triphenylphosphine, and $\mathrm{N}$-methylpyrrolidinone at $80^{\circ} \mathrm{C}$ for 2 hours; (C) reaction in the presence of sodium azide and $\mathrm{N}$-methylpyrrolidinone at $80^{\circ} \mathrm{C}$ for 4 hours; (D) reaction in the presence of hydrazine monohydrate in water at $100^{\circ} \mathrm{C}$ for 10 hours; and $(E)$ reaction in the presence of the alkyne-terminated $P A M A M$ dendrons $(G=2,3)$, $\mathrm{CuSO}_{4}$ /sodium ascorbate, and dimethylformamide in water at $40^{\circ} \mathrm{C}$ for 24 hours. $\mathrm{n}=62$.

Abbreviations: Cs, chitosan; G, generation; PAMAM, poly(amidoamine).

\section{Hemolysis assay}

The hemolytic activity of Cs- $g$-PAMAM $(\mathrm{G}=2,3)$ was investigated according to our previous work. ${ }^{46}$ In brief, $2 \%$ RBC suspension was treated with Cs or Cs-g-PAMAM $(\mathrm{G}=2,3)$ solution at different concentrations $(25 \mu \mathrm{g} / \mathrm{mL}, 50 \mu \mathrm{g} / \mathrm{mL}$, and $100 \mu \mathrm{g} / \mathrm{mL}$ ) and incubated for 2 hours at $37^{\circ} \mathrm{C}$ with gentle shaking. The RBC suspension incubated with physiological saline using the exact same process was regarded as the control for comparison. The RBC suspension was incubated with Triton X-100 $(10 \%, \mathrm{v} / \mathrm{v})$ to obtain complete hemolysis. Two hours later, the samples were viewed under an optical microscope using a magnification of $\times 100$. Then the RBC suspension was centrifuged at $1,000 \times g$ for 10 minutes. The supernatants were assayed for the absorbance of released hemoglobin at $540 \mathrm{~nm}$. The degree of hemolysis was determined by the following equation:

$$
\text { Hemolysis }(\%)=100 \times\left(\mathrm{Abs}-\mathrm{Ab}_{0}\right) /\left(\mathrm{Abs}_{100}-\mathrm{Abs}_{0}\right)
$$

where $\mathrm{Abs}, \mathrm{Abs}_{0}$, and $\mathrm{Abs}_{100}$ are the absorbances of test samples, the suspension treated with physiological saline, and the suspension of complete hemolysis treated with Triton X-100 (10\%, v/v), respectively.

\section{Atomic force microscopic examination}

The shape and roughness of RBCs were examined using atomic force microscopy (AFM) as described previously. ${ }^{47}$ In brief, rat RBCs were fixed by addition of $1 \%$ glutaraldehyde, and $25 \mu \mathrm{L}$ of each sample was applied to standard microscope slides. After air-drying, the samples were gently rinsed with deionized water to remove salt crystals and then air-dried again before analysis. All AFM images and roughness values (Rms) accordant with the images were obtained with an atomic force microscope (Autoprobe CP Research 
Inc, Albuquerque, NM, USA). Three independently produced samples were analyzed. The mean surface Rms of RBCs from different preparations was measured with high-resolution images in a scanned area of $1 \times 1 \mu \mathrm{m}^{2}$.

\section{Cytotoxicity assay}

The effects of Cs and Cs-g-PAMAM on the viability of human kidney $293 \mathrm{~T}$ cells were determined using the MTT assay as described previously by us. ${ }^{48,49}$ Cells were seeded in the 96-well plate at a density of $1 \times 10^{4}$ cells per well and cultured for 24 hours. After an additional incubation with different concentrations of Cs- $g$-PAMAM $(\mathrm{G}=2,3)$ and $\mathrm{Cs}$ for 24 hours, the medium was changed with DMEM containing $20 \mu \mathrm{L}$ of MTT solution $(0.5 \mathrm{mg} / \mathrm{mL})$. After further incubation for 4 hours, the reaction product was solubilized with $150 \mu \mathrm{L}$ DMSO. The absorbance value was measured at $570 \mathrm{~nm}$ using a plate reader (Bio-Rad Inc, Hercules, CA, USA). Cell viability (\%) was calculated according to the following equation: cell viability $(\%)=\left[A_{570}(\right.$ sample $) / A_{570}$ (control) $\times 100 \%$, where $A_{570}$ (sample) was obtained in the presence of polymers and $A_{570}$ (control) was obtained in the absence of polymers.

\section{Statistical analysis}

Data are expressed as mean \pm standard deviation of at least three different experiments and analyzed by one-way analysis of variance and Tukey's test. Statistical analysis was performed using SPSS version 11.5. Only values with $P<0.05$ were considered statistically significant.

\section{Results}

\section{Effects of Cs-g-PAMAM ( $\mathrm{G}=2,3)$ on the lysis of rat RBCs}

The RBC lysis method is widely used to study polymermembrane interaction. ${ }^{50}$ To check whether Cs-g-PAMAM $(\mathrm{G}=2,3)$ caused membrane rupture of rat $\mathrm{RBCs}$, we incubated RBCs with Cs- $g$-PAMAM $(\mathrm{G}=2,3)$ at $25 \mu \mathrm{g} / \mathrm{mL}, 50 \mu \mathrm{g} / \mathrm{mL}$, and $100 \mu \mathrm{g} / \mathrm{mL}$ and measured the release of hemoglobin, which indicates membrane disruption and $\mathrm{RBC}$ lysis. As shown in Figure 2, treatment of RBCs with Cs- $g$-PAMAM ( $\mathrm{G}=2$ or 3 ) at $50 \mu \mathrm{g} / \mathrm{mL}$ and $100 \mu \mathrm{g} / \mathrm{mL}$ induced a slightly higher hemolysis than Cs; Cs-g-PAMAM ( $\mathrm{G}=3$ ) caused a slightly higher hemolysis than Cs- $g$-PAMAM $(\mathrm{G}=2)$; but all values were $<5.0 \%$. When rat RBCs were treated with Cs at $25 \mu \mathrm{g} / \mathrm{mL}, 50 \mu \mathrm{g} / \mathrm{mL}$, and $100 \mu \mathrm{g} / \mathrm{mL}$ for 2 hours, the hemolysis rate was $2.12 \% \pm 0.56 \%, 2.79 \% \pm 0.73 \%$, and $2.84 \% \pm 0.22 \%$, respectively. Treatment of the rat RBCs with Cs- $g$-PAMAM(G=2) at $25 \mu \mathrm{g} / \mathrm{mL}, 50 \mu \mathrm{g} / \mathrm{mL}$, and $100 \mu \mathrm{g} / \mathrm{mL}$ for 2 hours resulted in hemolysis rates of $2.50 \% \pm 0.44 \%$,

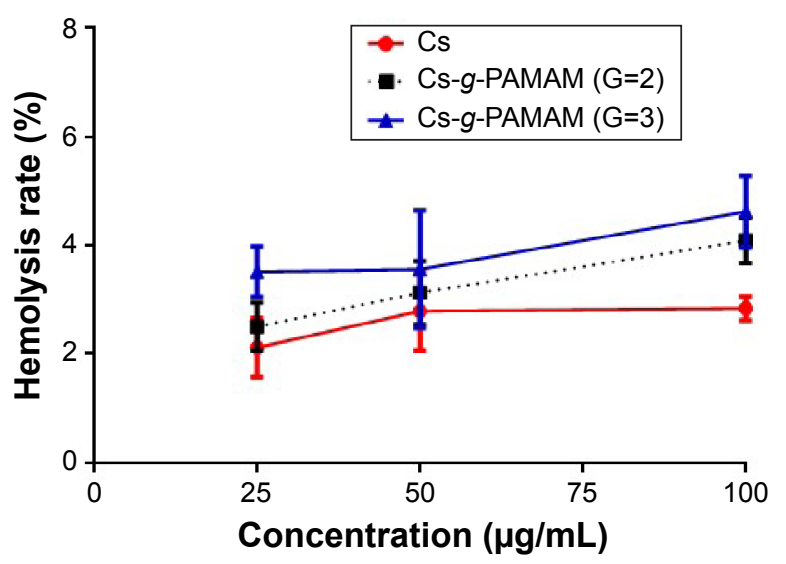

Figure 2 Effects of the concentration of Cs, Cs-g-PAMAM ( $G=2)$, and Cs-g-PAMAM $(\mathrm{G}=3)$ on the hemolysis of rat RBCs.

Notes: Data are the mean \pm standard deviation of three independent experiments. Rat RBCs were collected and incubated with the compound studied, physiological saline, or $10 \%$ Triton $\mathrm{X}-100$ for 2 hours at $37^{\circ} \mathrm{C}$ with gentle shaking. Two hours later, the samples were viewed under an optical microscope and the RBC suspension was centrifuged to obtain the released hemoglobin from the supernatants. The absorbance was measured at $540 \mathrm{~nm}$, and the hemolysis rate was calculated as percentage.

Abbreviations: Cs, chitosan; G, generation; PAMAM, poly(amidoamine); RBC, red blood cell.

$3.13 \% \pm 0.58 \%$, and $4.09 \% \pm 0.42 \%$, respectively. These values, however, were $3.51 \% \pm 0.46 \%, 3.56 \% \pm 1.08 \%$, and $4.62 \% \pm 0.66 \%$ when RBCs were treated with Cs-g-PAMAM ( $\mathrm{G}=3$ ) at $25 \mu \mathrm{g} / \mathrm{mL}, 50 \mu \mathrm{g} / \mathrm{mL}$, and $100 \mu \mathrm{g} / \mathrm{mL}$ for 2 hours, respectively (Figure 2).

The results showed that the hemolysis rate of RBCs with Cs was a little lower than that caused by Cs- $g$-PAMAM $(\mathrm{G}=2,3)$. The slightly higher hemolysis of Cs- $g$-PAMAM $(\mathrm{G}=2,3)$ might be due to the fact that PAMAM dendrimers contain amino terminals that pose certain cytotoxicity to the RBCs. Meanwhile, the results demonstrated that hemolysis rate of RBCs with Cs- $g$-PAMAM $(\mathrm{G}=3)$ was higher than that caused by Cs- $g$-PAMAM $(\mathrm{G}=2)$ at the same concentration, indicating that the cytotoxicity was related to the dendron number. All the hemolysis rates caused by Cs and Cs- $g$ PAMAM with different dendron generations $(\mathrm{G}=2,3)$ were $<5.0 \%$, indicating that Cs-g-PAMAM was not hemolytic according to Standard Practice for Assessment of Hemolytic Properties of Materials F756-93 standards. ${ }^{51}$

\section{Effects of Cs-g-PAMAM $(\mathrm{G}=2,3)$ on the shape and roughness of RBCs using optical microscopy and AFM}

Next, we investigated the effects of Cs- $g$-PAMAM $(\mathrm{G}=2,3)$ on the shape and morphology of rat RBCs using optical microscopy and AFM. Figure 3 shows the changes of the $\mathrm{RBC}$ shape in response to treatment with Cs-g-PAMAM $(\mathrm{G}=2,3), \mathrm{Cs}$, physiological saline, or $10 \%$ Triton $\mathrm{X}-100$ under 

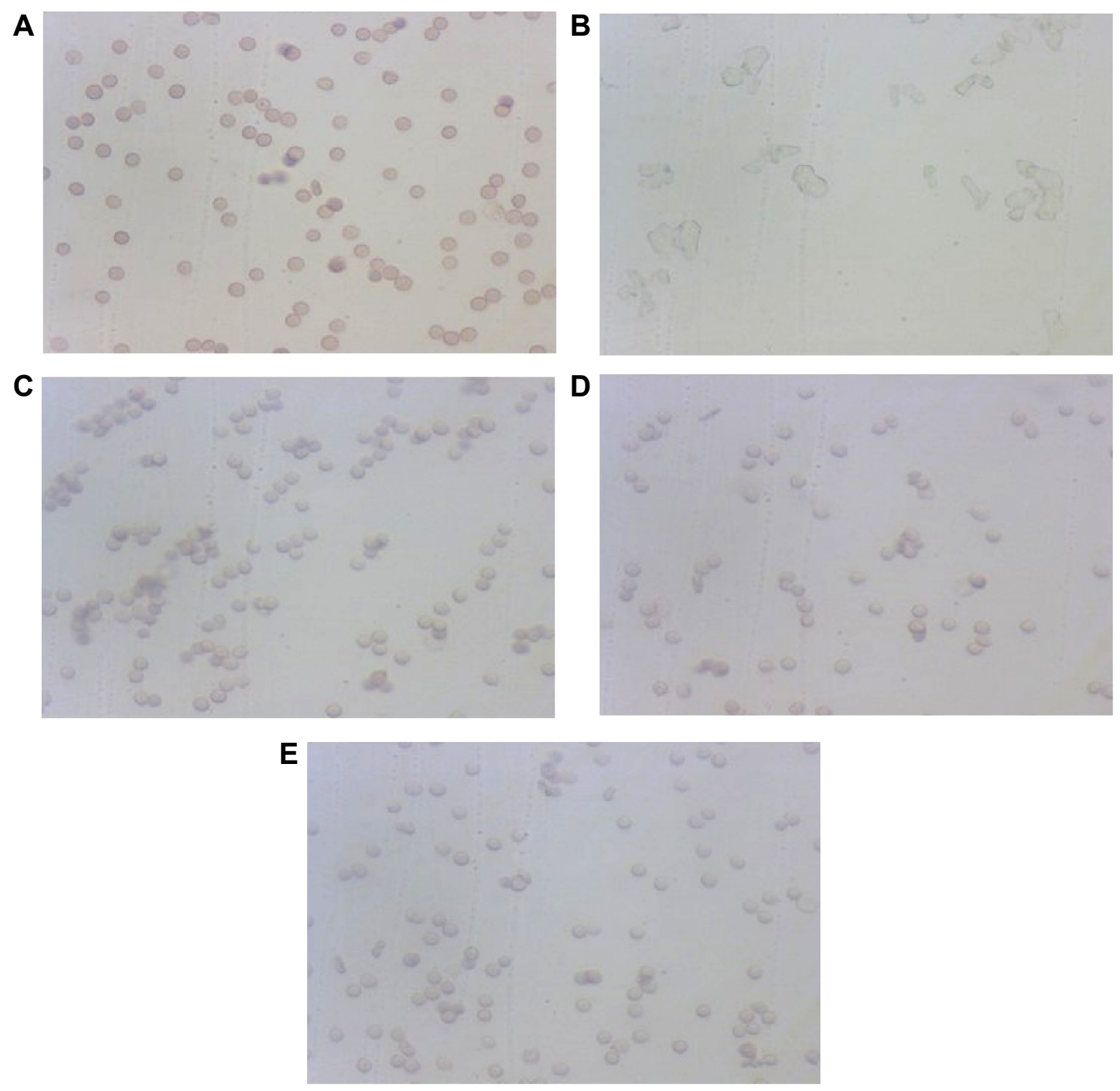

Figure 3 Representative images of rat RBCs in different solutions under light microscopy.

Notes: (A) Cell image in $0.9 \% \mathrm{NaCl}$ solution, (B) cell image in $10 \%$ Triton X-100, (C) cell image in Cs at $100 \mu \mathrm{g} / \mathrm{mL}$, (D) cell image in Cs-g-PAMAM (G=2) at I00 $\mu g / \mathrm{mL}$, and $(\mathbf{E})$ cell image in Cs-g-PAMAM (G=3) at $100 \mu \mathrm{g} / \mathrm{mL}$. Magnification: $\times 100$.

Abbreviations: Cs, chitosan; G, generation; PAMAM, poly(amidoamine); RBC, red blood cell.

light microscopy. The RBCs treated with physiological saline were normal disk shaped (diskocytes) (Figure 3A). Treatment of RBCs with $10 \%$ Triton X-100 caused a complete hemolysis (Figure 3B). Figure 3C-E shows the shape of erythrocytes when in contact with Cs- $g$-PAMAM $(\mathrm{G}=2,3)$ or Cs at $100 \mu \mathrm{g} / \mathrm{mL}$. Treatment of RBCs with $100 \mu \mathrm{g} / \mathrm{mL}$ Cs- $g$-PAMAM $(\mathrm{G}=3)$ induced echinocytic transformation; RBCs displayed characteristic irregular contour due to the folding of the periphery. Drephanocyte-like RBCs were also observed when treated with $100 \mu \mathrm{g} / \mathrm{mL}$ Cs-g-PAMAM $(G=3)$. Erythrocytes underwent similar shape transition upon treatment with Cs- $g$-PAMAM $(\mathrm{G}=2)$ or Cs. For Cs and Cs$g$-PAMAM $(\mathrm{G}=2,3)$, similar changes in the shape of RBCs occurred at a higher concentration.

RBCs have been extensively studied by AFM due to their disease-sensitive shape, the simplicity in morphology and biochemistry of plasma membrane, and other factors. ${ }^{52}$ As shown in Figure 4, our AFM examinations demonstrated that hemocompatibility of Cs could be remarkably affected by incorporation of PAMAM dendrons. When Cs or Cs- $g$ PAMAM molecules $(G=2,3)$ were present on the $R B C$ surface, there were two possible targets for their binding: lipids 
A

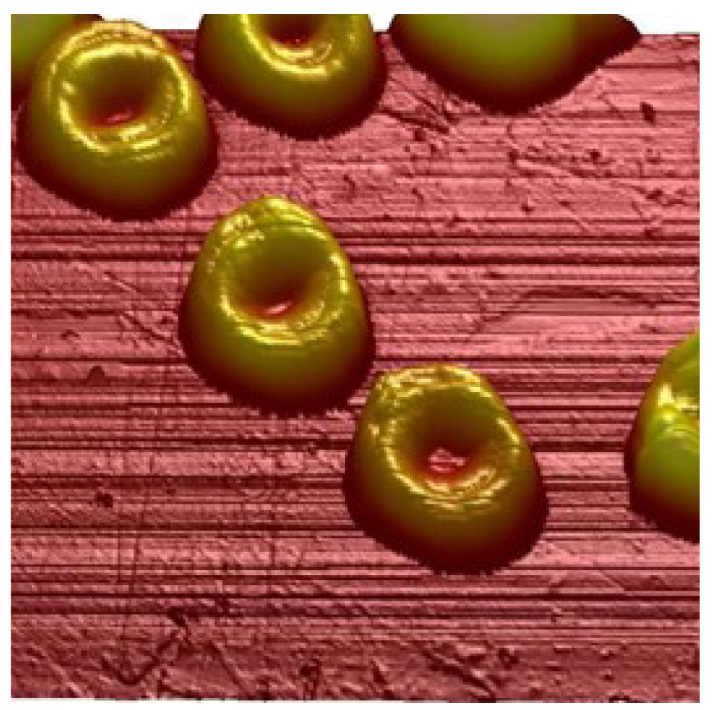

C

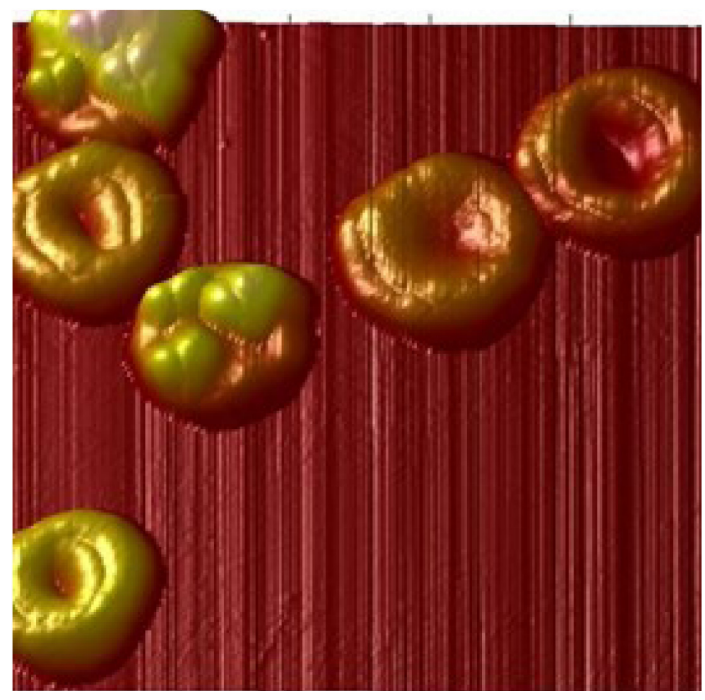

B

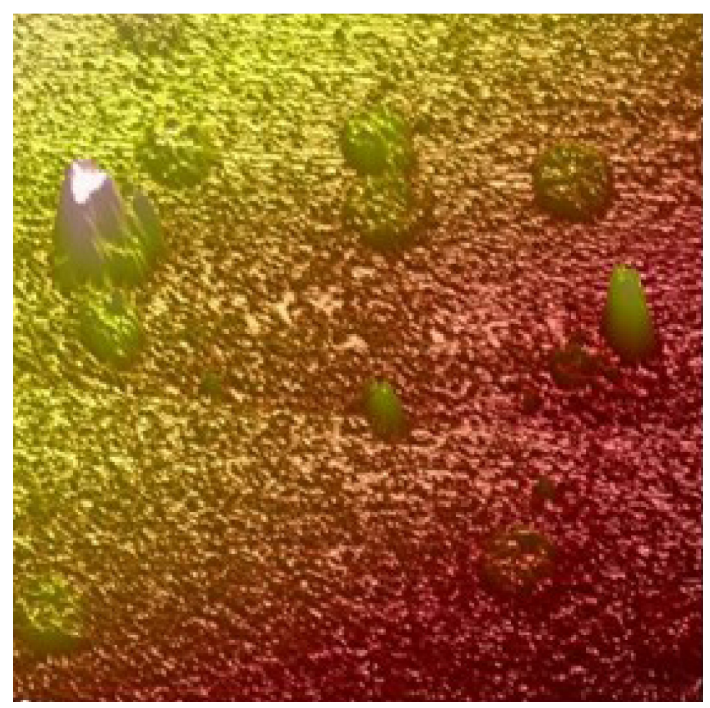

D

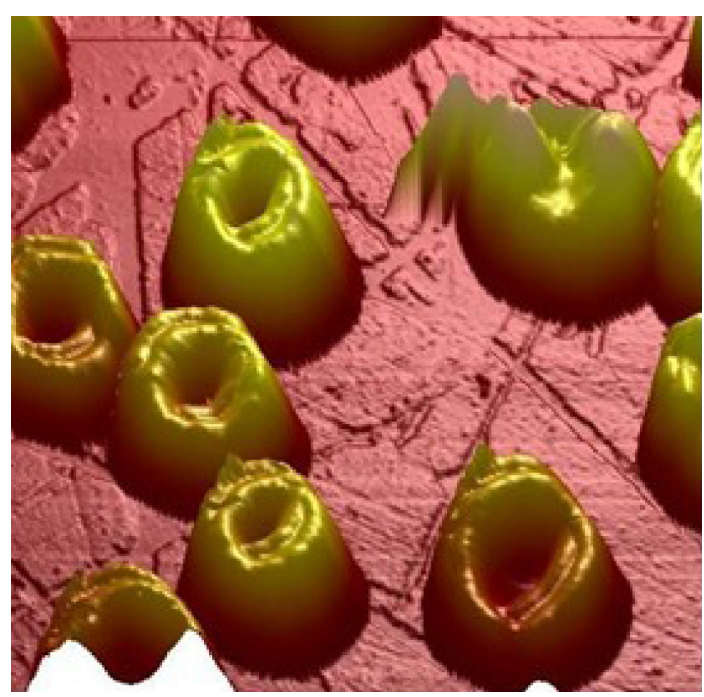

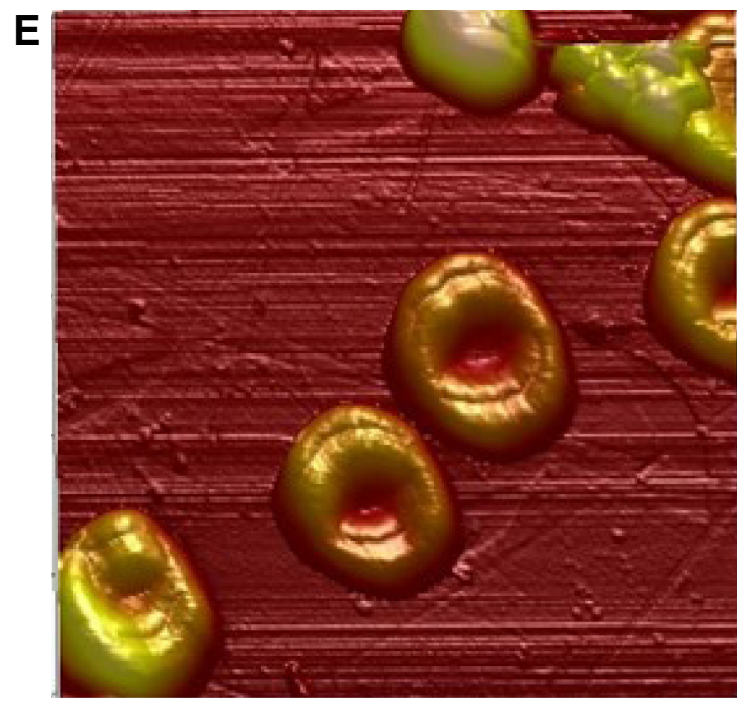

Figure 4 Representative images of RBCs in different solutions obtained from AFM.

Notes: Rat RBCs were fixed by addition of I\% glutaraldehyde, and $25 \mu \mathrm{L}$ of each sample was applied to standard microscope slides. After air-drying, the samples were gently rinsed with deionized water to remove salt crystals and then air-dried again before analysis. All images were obtained with an AFM. (A) $0.9 \% \mathrm{NaCl}$ solution, (B) $10 \%$ Triton X-100, (C) Cs at $100 \mu \mathrm{g} / \mathrm{mL}$, (D) Cs-g-PAMAM (G=2) at $100 \mu \mathrm{g} / \mathrm{mL}$, and (E) Cs-g-PAMAM (G=3) at $100 \mu \mathrm{g} / \mathrm{mL}$.

Abbreviations: AFM, atomic force microscopy; Cs, chitosan; G, generation; PAMAM, poly(amidoamine); RBC, red blood cell. 
and membrane proteins. The formation of echinocytes in our experiments could be due to partial $\mathrm{Cs}$ and Cs-g-PAMAM $(\mathrm{G}=2,3)$ incorporation into the lipid bilayers or due to pulling out of the outer monolayer by $\mathrm{Cs}$ and Cs- $g$-PAMAM $(\mathrm{G}=2,3)$ molecules.

Hemolysis rate and Rms are the quantitative indexes used to analyze the injury to RBCs caused by these materials, and a low hemolysis rate and Rms mean that the materials are biocompatible. Figure 5 presents the mean surface Rms of RBCs incubated with physiological saline, Cs, or Cs-gPAMAM ( $\mathrm{G}=2$ and 3$)$ at $100 \mu \mathrm{g} / \mathrm{mL}$. The Rms value of Cs, Cs-g-PAMAM ( $\mathrm{G}=2)$, and Cs- $g$-PAMAM (G=3) was significantly larger compared with that in physiological saline $(5.53 \mathrm{~nm}$ versus $34.70 \mathrm{~nm}, 31.43 \mathrm{~nm}$, and $58.17 \mathrm{~nm}$, respectively; $P<0.01)$. However, the Rms value of RBCs treated with $\mathrm{Cs}$ and $\mathrm{Cs}-\mathrm{g}$-PAMAM ( $\mathrm{G}=2$ and 3 ) showed no difference $(P>0.05)$. The results demonstrated that both $\mathrm{Cs}$ and Cs-g-PAMAM ( $\mathrm{G}=2$ and 3 ) significantly increased the roughness of RBCs.

\section{Effects of Cs and Cs-g-PAMAM on the viability of RBCs using the MTT assay}

The cytotoxicity of Cs- $g$-PAMAM $(\mathrm{G}=2,3)$ and $\mathrm{Cs}$ in the 293T cell line was evaluated by the MTT assay, and the results are shown in Figure 6. Treatment with Cs-g-PAMAM $(\mathrm{G}=2,3)$ or Cs at $25 \mu \mathrm{g} / \mathrm{mL}, 50 \mu \mathrm{g} / \mathrm{mL}$, and $100 \mu \mathrm{g} / \mathrm{mL}$ only slightly reduced the viability of RBCs. The results showed that all the PAMAM dendrimers had a low cytotoxicity toward RBCs.

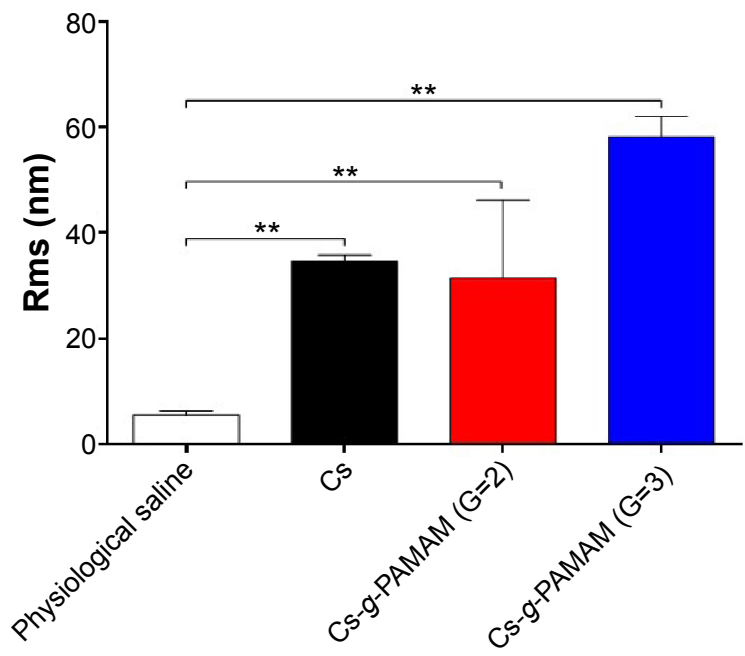

Figure 5 Mean surface roughness (Rms) of RBCs treated with saline solution, Cs, and Cs-g-PAMAM $(\mathrm{G}=2,3)$ at $100 \mu \mathrm{g} / \mathrm{mL}$.

Note: Data are the mean \pm standard deviation of three independent experiments. $* * P<0.0$ l versus the saline group by one-way ANOVA.

Abbreviations: ANOVA, analysis of variance; Cs, chitosan; G, generation; PAMAM, poly(amidoamine); RBC, red blood cell.

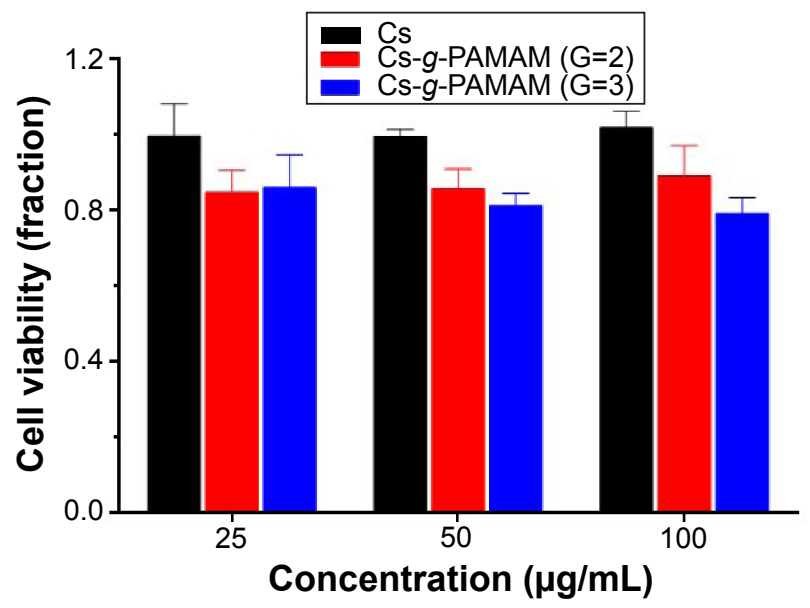

Figure 6 Cytotoxicity of Cs-g-PAMAM at various concentrations in human kidney 293T cells.

Notes: Data are the mean \pm standard deviation of three independent experiments. The viability of 293 T cells was determined using the MTT assay. Cells were seeded in the 96-well plate at a density of $1 \times 10^{4}$ cells per well and cultured for 24 hours. Cells were treated with Cs-g-PAMAM (G=2,3) or chitosan for 24 hours, and $20 \mu \mathrm{L}$ MTT solution $(0.5 \mathrm{mg} / \mathrm{mL})$ was added to each well. After further incubation for 4 hours, the reaction product was solubilized with $150 \mu \mathrm{L}$ DMSO and the absorbance was measured at $570 \mathrm{~nm}$.

Abbreviations: Cs, chitosan; DMSO, dimethyl sulfoxide; G, generation; MTT, methyl thiazolyl tetrazolium; PAMAM, poly(amidoamine).

\section{Discussion}

Presently, nanomaterial production and use continue to become more prevalent, and consistent and accurate toxicity evaluation is crucial for the ability to properly regulate these nanomaterials. Because of quantum size effects and large surface area-tovolume ratio, nanomaterials have unique physical, chemical, and biological properties compared with their larger counterparts. Nanoparticles may induce the production of proinflammatory cytokines and stimulate the immune system, leading to inflammation, immune responses, allergy/hypersensitivity, and activation or inhibition of immune cells. ${ }^{53,54}$ Many types of nanoparticles can translocate from their site of deposition to distant sites, such as the brain and bone marrow, via blood circulation. Some nanomaterials are toxic to human tissues/ organs and cells, resulting in increased oxidative stress, generation of reactive oxygen/nitrogen species, and programmed cell death including apoptosis and autophagy. ${ }^{55-57}$ The toxicity of nanoparticles is mainly determined by their composition, size, shape, and surface reactivity with cells and cellular components. On June 24, 2014, the US Food and Drug Administration (FDA) issued one draft and three final guidance documents related to the use of nanotechnology in regulated products. FDA regulates nanotechnology products under existing statutory authorities, in accordance with the specific legal standards applicable to each type of product under its jurisdiction.

Dendrimers possess several advantages for drug and gene delivery: 1) monodispersity or low polydispersity, allowing 
for reproducible pharmacokinetic behavior; 2) globular shape of higher-generation dendrimers, affecting their biological and rheological properties; and 3) controlled multivalency, which can be used to attach several functional molecules, eg, drugs, imaging agents, cell-penetrating peptides, targeting ligands, and/or solubilizing moieties..$^{20-23,58}$ These features offer an extraordinary combination of guest-host and interfacial surface functional advantages for the delivery of drugs, genes, and imaging agents and tissue-targeting applications. ${ }^{23}$ Dendrimers have shown enormous potential as nanocarrier/ delivery systems because they can cross cell barriers by both paracellular and transcellular pathways. Depending on surface chemistry, PAMAM dendrimers can open the tight junctions of epithelial barriers, which is in part mediated by internalization of the dendrimers. ${ }^{59}$ Because the relationships among dendrimer architecture, biocompatibility, circulation time, and release kinetics have been already established, the design of dendrimers as drug delivery carriers can be optimized readily. For example, PEGylation can be used to increase water solubility, permeability, stability; dendrimer size can be properly retained to have favorable retention and biodistribution characteristics; therapeutic agents can be internalized into the void space between the branches or covalently attached to surface groups; and addition of targeting moieties/ligands can bring about binding to the dendrimer surface to selectively deliver the drug to diseased cells. Dendrimers usually cross cellular barriers by endocytosis; ${ }^{60,61}$ thus, they are entrapped in endososomes and only a small amount of the active drug can reach the intracellular target. However, most dendrimers exhibit toxic and hemolytic activity due to their positively charged surface. ${ }^{62}$

The chemical combination of PAMAM dendrimers with Cs may provide both biomacromolecular and biofunctional characteristics, with improved water solubility and low toxicity. Sarkar and Kundu ${ }^{29}$ demonstrated that PAMAMconjugated Cs showed a significantly increased DNAbinding capability and transfection efficiency (even better than that with polyethylenimine). For any nanostructured drug delivery system, it must be safe and biocompatible, with no or low immunostimulating activity. Because most of these enter the blood circulation to some extent together with the delivered drug, they should not be hemolytic. In the circulation, under physiological conditions, the highly deformable RBCs have the shape of a biconcave disk (socalled diskocytes). Diskocytes either transform to echinocytes (crenated cells) or stomatocytes (cup-shaped cells) under the influence of intrinsic or extrinsic factors. ${ }^{63-66}$ Furthermore, the erythrocyte's outer surface is negatively charged, which prevents RBCs from aggregating with each other and from adhering to the walls of blood vessels. Cationic dendrimers can interact with the lipids and proteins of RBC membranes through electrostatic attractions. ${ }^{62,67}$ PAMAM dendrimers have been widely applied in gene delivery; Cs can reduce the charges by shielding the PAMAM dendrimer surface and can be used safely as an alternate, efficient delivery vector in gene therapy. ${ }^{29,68-70}$ However, the application of PAMAM is significantly restricted due to its harmful hematologic effect caused by its cationic charges, which prevents systemic administration. The cytotoxic effects of PAMAM dendrimers on RBCs were found to be time, concentration, and charge dependent. The molecular weight, hydrophobicity, generation, basic $\mathrm{pH}$, cationic charge density, and bulk structure of the PAMAM dendrimers were key factors that determined the interaction with the RBC membranes and, consequently, the cell damage. ${ }^{37,38,71}$ Many studies have demonstrated that the hematologic toxicity of PAMAM dendrimers could be greatly diminished by PEGylation, ${ }^{36}$ zwitterionic $\mathrm{Cs},{ }^{68}$ and grafted $N$-maleyl $\mathrm{CS},{ }^{13}$ which showed no noticeable hemolytic effects, indicating no detectable disturbance of the $\mathrm{RBC}$ membranes. This is further supported by our finding in this study, wherein a hemolysis rate $<5.0 \%$ was observed for Cs-g-PAMAM $(\mathrm{G}=2,3)$ in rat $\mathrm{RBCs}$.

The hemolytic effect of dendrimers is concerned with the nature of materials, such as composition, surface roughness, and related charges. The shape change and the hemolysis of RBCs induced by $\mathrm{Cs}$ and $\mathrm{Cs}-\mathrm{g}$-PAMAM $(\mathrm{G}=2,3)$ might be due to their interaction with the erythrocyte membrane. Some dendrimers can interact with lipids by hydrophobic interactions between lipid acyl chains and the hydrophobic dendrimer interior, depending on the size and charge of the molecule and the phase of lipids. ${ }^{72,73}$ It is well known that the surface of a normal erythrocyte is negatively charged due to the presence of glycolipids and some glycated integral and peripheral proteins. ${ }^{65}$ Electrostatic repulsion among RBCs prevents their self-aggregation and adhesion to the walls of blood vessels. Cationic Cs and Cs-g-PAMAM $(\mathrm{G}=2,3)$ were supposed to come close to the RBC surface as a result of electrostatic attraction. Thus, the formation of erythrocyte aggregates might be the consequence of their cross-linking by $\mathrm{Cs}$ and $\mathrm{Cs}-g$-PAMAM $(\mathrm{G}=2,3)$. Further studies are needed to reveal the mechanism of $\mathrm{Cs}$ and $\mathrm{Cs}-\mathrm{g}$-PAMAM $(\mathrm{G}=2,3)-$ protein interactions.

The interaction of dendrimers with cellular membrane is complicated. Dendrimers either create holes in a bilayer or can be incorporated into the lipid structure. ${ }^{74,75}$ Highergeneration dendrimers cause greater disturbances in a lipid 
bilayer, and positively charged dendrimers interact more effectively with liposomes. It has been proposed that at low concentrations, dendrimers can traverse the bilayer, while at higher concentrations, dendrimer:lipid micelles are generated. The toxicity of PAMAM dendrimers generally increases with increasing generation number, which has been ascribed to the increased number of positive charges per molar concentration and thus increased contact area of the dendrimer with the cell membrane. The electrostatic interactions of cationic dendrimers with cell membranes probably induces nanoscale-level hole formation and membrane destabilization mechanisms. ${ }^{76}$ Therefore, removal of the positive charges through functionalization of external groups from the surface of the dendrimers can minimize the membrane interactions.

The cytotoxicity of PAMAM dendrimers is mainly determined by their concentration, generation, and surface charge. Both anionic and neutral PAMAM dendrimers are remarkably less cytotoxic and permeable than cationic dendrimers; dendrimers of a lower generation (ie, $\mathrm{G}=0-1$ ) are often less cytotoxic than those of a higher generation (ie, $\mathrm{G}=2-4$ ). ${ }^{23,75,77}$ AFM studies have indicated that polycationic dendrimers induce hole formation and/or expansion of preexisting defects in supported lipid bilayers, whereas hydroxyl-containing neutral polymers do not show these disturbing effects. ${ }^{76}$ The cytotoxicity of cationic PAMAM dendrimers toward RBCs is mainly determined by their surface charge and hydrophobicity. ${ }^{37}$ Amine-terminated PAMAM dendrimers are rarely used in systemic applications due to their cytotoxicity and risk of opsonization caused by their cationic charges. Such undesirable effects may be attenuated by shielding the PAMAM dendrimer surface with polymers that reduce the charges, and modifications of PAMAM dendrimers represent an easy approach to improve their biocompatibility. For example, conjugation or hybrid formation with $N$-maleyl chitosan, ${ }^{13,14}$ carboxymethyl chitosan, ${ }^{69,78}$ chitosan, ${ }^{79}$ zwitterionic chitosan, ${ }^{68}$ arginine, ${ }^{33,80}$ carboxybetaine acrylamide, ${ }^{81}$ PEGylation, ${ }^{36}$ 2-[2-(2-methoxyethoxy)ethoxy]acetic acid, ${ }^{35}$ gold nanoparticles, ${ }^{82}$ oleic acid-functionalized graphene, ${ }^{83}$ or quantum dots ${ }^{84,85}$ has been used to improve the efficacy of drug/gene delivery and reduce the cytotoxicity.

In summary, dendrimers are well-defined highly branched structures that have attracted much interest in biomedical applications. ${ }^{23}$ Among their potential biomedical applications are drug and gene delivery to target cells across the membrane, a complex structure composed of lipids and embedded proteins. To understand dendrimers' mechanism of action and to evaluate their biosafety and biocompatibility, their interactions with RBCs need to be unraveled. The dendronized Cs derivatives Cs- $g$-PAMAM $(\mathrm{G}=2,3)$ caused a low level of morphology change and membrane disruption of rat RBCs, indicating an excellent hemocompatibility with RBCs. Further safety and biocompatibility evaluations are needed for the dendronized Cs derivatives Cs-g-PAMAM $(G=2,3)$. Our findings prove helpful for a better understanding of the advantages of combining PAMAM dendrimers and Cs to design and develop new, safe, and effective drug and gene delivery vehicles.

\section{Acknowledgments}

The authors gratefully acknowledge the financial support for the research (grant numbers B2011003, S2012010008187, 2013B021800073, 201310571019, 1057113039, and 2014108101049). This work was also supported in part by the China Scholarship Council (numbers 201308440229 and 201408440141).

\section{Disclosure}

The authors report no conflicts of interest in this work.

\section{References}

1. Upadhyaya L, Singh J, Agarwal V, Tewari RP. The implications of recent advances in carboxymethyl chitosan based targeted drug delivery and tissue engineering applications. J Control Release. 2014;186: 54-87.

2. Singh B, Choi YJ, Park IK, Akaike T, Cho CS. Chemical modification of chitosan with $\mathrm{pH}$-sensitive molecules and specific ligands for efficient DNA transfection and siRNA silencing. J Nanosci Nanotechnol. 2014; 14(1):564-576.

3. Du H, Yang X, Zhai G. Design of chitosan-based nanoformulations for efficient intracellular release of active compounds. Nanomedicine (Lond). 2014;9(5):723-740.

4. Ghaz-Jahanian MA, Abbaspour-Aghdam F, Anarjan N, Berenjian A, Jafarizadeh-Malmiri H. Application of chitosan-based nanocarriers in tumor-targeted drug delivery. Mol Biotechnol. 2015;57(3):201-218.

5. Han L, Tang C, Yin C. Enhanced antitumor efficacies of multifunctional nanocomplexes through knocking down the barriers for siRNA delivery. Biomaterials. 2015;44:111-121.

6. Li F, Zhang X, Li H, Xiang L, Chen Y. Preparation of self-assembled nanoparticles of chitosan oligosaccharide-graft-polycaprolactone as a carrier of bovine serum albumin drug. Biomed Mater Eng. 2014;24(6): 2041-2048.

7. Almada M, Burboa MG, Robles E, Gutierrez LE, Valdes MA, Juarez J. Interaction and cytotoxic effects of hydrophobized chitosan nanoparticles on MDA-MB-231, HeLa and Arpe-19 cell lines. Curr Top Med Chem. 2014;14(6):692-701.

8. Zhao Q, Zhang J, Song L, et al. Polysaccharide-based biomaterials with on-demand nitric oxide releasing property regulated by enzyme catalysis. Biomaterials. 2013;34(33):8450-8458.

9. Jia M, Li Y, Yang X, et al. Development of both methotrexate and mitomycin $\mathrm{C}$ loaded PEGylated chitosan nanoparticles for targeted drug codelivery and synergistic anticancer effect. ACS Appl Mater Interfaces. 2014;6(14):11413-11423.

10. Lin WJ, Hsu WY. Pegylation effect of chitosan based polyplex on DNA transfection. Carbohydr Polym. 2015;120:7-14. 
11. Tang S, Huang Z, Zhang H, Wang Y, Hu Q, Jiang H. Design and formulation of trimethylated chitosan-graft-poly(epsilon-caprolactone) nanoparticles used for gene delivery. Carbohydr Polym. 2014;101: 104-112.

12. Benediktsdottir BE, Baldursson O, Masson M. Challenges in evaluation of chitosan and trimethylated chitosan (TMC) as mucosal permeation enhancers: From synthesis to in vitro application. J Control Release. 2014; 173:18-31.

13. Sarkar K, Chatterjee A, Chakraborti G, Kundu PP. Blood compatible $\mathrm{N}$-maleyl chitosan-graft-PAMAM copolymer for enhanced gene transfection. Carbohydr Polym. 2013;98(1):596-606.

14. Sarkar K, Kundu PP. Preparation of low molecular weight $N$-maleated chitosan-graft-PAMAM copolymer for enhanced DNA complexation. Int J Biol Macromol. 2012;51(5):859-867.

15. Ghorbani FM, Kaffashi B, Shokrollahi P, Seyedjafari E, Ardeshirylajimi A. PCL/chitosan/Zn-doped nHA electrospun nanocomposite scaffold promotes adipose derived stem cells adhesion and proliferation. Carbohydr Polym. 2015;118:133-142.

16. Sawdon AJ, Peng CA. Ring-opening polymerization of epsiloncaprolactone initiated by ganciclovir (GCV) for the preparation of GCV-tagged polymeric micelles. Molecules. 2015;20(2):2857-2867.

17. Lu B, Wang CF, Wu DQ, Li C, Zhang XZ, Zhuo RX. Chitosan based oligoamine polymers: synthesis, characterization, and gene delivery. J Control Release. 2009;137(1):54-62.

18. Mitra RN, Han Z, Merwin M, Al Taai M, Conley SM, Naash MI. Synthesis and characterization of glycol chitosan DNA nanoparticles for retinal gene delivery. Chem Med Chem. 2014;9(1):189-196.

19. Yhee JY, Song S, Lee SJ, et al. Cancer-targeted MDR-1 siRNA delivery using self-cross-linked glycol chitosan nanoparticles to overcome drug resistance. J Control Release. 2015;198:1-9.

20. Kannan RM, Nance E, Kannan S, Tomalia DA. Emerging concepts in dendrimer-based nanomedicine: from design principles to clinical applications. J Intern Med. 2014;276(6):579-617.

21. Kesharwani P, Iyer AK. Recent advances in dendrimer-based nanovectors for tumor-targeted drug and gene delivery. Drug Discov Today. Epub 2015.

22. Wu LP, Ficker M, Christensen JB, Trohopoulos PN, Moghimi SM. Dendrimers in medicine: therapeutic concepts and pharmaceutical challenges. Bioconjug Chem. Epub 2015.

23. Menjoge AR, Kannan RM, Tomalia DA. Dendrimer-based drug and imaging conjugates: design considerations for nanomedical applications. Drug Discov Today. 2010;15(5-6):171-185.

24. Wei T, Chen C, Liu J, et al. Anticancer drug nanomicelles formed by self-assembling amphiphilic dendrimer to combat cancer drug resistance. Proc Natl Acad Sci U S A. 2015;112(10):2978-2983.

25. Lu F, Mencia A, Bi L, Taylor A, Yao Y, HogenEsch H. Dendrimer-likeD-glucan nanoparticles activate dendritic cells and are effective vaccine adjuvants. J Control Release. 2015;204:51-59.

26. Santos JL, Oramas E, Pego AP, Granja PL, Tomas H. Osteogenic differentiation of mesenchymal stem cells using PAMAM dendrimers as gene delivery vectors. J Control Release. 2009;134(2):141-148.

27. Nam HY, Nam K, Hahn HJ, et al. Biodegradable PAMAM ester for enhanced transfection efficiency with low cytotoxicity. Biomaterials. 2009; 30(4):665-673.

28. Yuan Q, Yeudall WA, Yang H. PEGylated polyamidoamine dendrimers with bis-aryl hydrazone linkages for enhanced gene delivery. Biomacromolecules. 2010;11(8):1940-1947.

29. Sarkar K, Kundu PP. PAMAM conjugated chitosan through naphthalimide moiety for enhanced gene transfection efficiency. Carbohydr Polym. 2013;98(1):495-504.

30. Liu X, Liu C, Catapano CV, Peng L, Zhou J, Rocchi P. Structurally flexible triethanolamine-core poly(amidoamine) dendrimers as effective nanovectors to deliver RNAi-based therapeutics. Biotechnol Adv. 2014; 32(4):844-852.

31. Sabahi Z, Samani SM, Dehshahri A. Conjugation of poly(amidoamine) dendrimers with various acrylates for improved delivery of plasmid encoding interleukin-12 gene. J Biomater Appl. 2015;29(7):941-953.
32. Zheng W, Cao C, Liu Y, et al. Multifunctional polyamidoaminemodified selenium nanoparticles dual-delivering siRNA and cisplatin to A549/DDP cells for reversal multidrug resistance. Acta Biomater. 2015; 11:368-380.

33. Liu X, Liu C, Zhou J, et al. Promoting siRNA delivery via enhanced cellular uptake using an arginine-decorated amphiphilic dendrimer. Nanoscale. 2015;7(9):3867-3875.

34. Janaszewska A, Studzian M, Petersen JF, Ficker M, Christensen JB, Klajnert-Maculewicz B. PAMAM dendrimer with 4-carbomethoxypyrrolidone - in vitro assessment of neurotoxicity. Nanomedicine. 2015;11(2):409-411.

35. Movellan J, Gonzalez-Pastor R, Martin-Duque P, Sierra T, de la Fuente JM, Serrano JL. New ionic bis-MPA and PAMAM dendrimers: a study of their biocompatibility and DNA-complexation. Macromol Biosci. Epub 2015.

36. Wang W, Xiong W, Zhu Y, Xu H, Yang X. Protective effect of PEGylation against poly(amidoamine) dendrimer-induced hemolysis of human red blood cells. J Biomed Mater Res B Appl Biomater. 2010;93(1):59-64.

37. Halets I, Shcharbin D, Klajnert B, Bryszewska M. Contribution of hydrophobicity, DNA and proteins to the cytotoxicity of cationic PAMAM dendrimers. Int J Pharm. 2013;454(1):1-3.

38. Lin J, Hua W, Zhang Y, et al. Effect of poly(amidoamine) dendrimers on the structure and activity of immune molecules. Biochim Biophys Acta. 2015;1850(2):419-425.

39. Deng JJ, Zhou YF, Xu B, Mai KJ, Deng YB, Zhang LM. Dendronized chitosan derivative as a biocompatible gene delivery carrier. Biomacromolecules. 2011;12(3):642-649.

40. Kostova EB, Beuger BM, Klei TR, et al. Identification of signalling cascades involved in red blood cell shrinkage and vesiculation. Biosci Rep. 2015;35(2):e00187.

41. Zarrin A, Foroozesh M, Hamidi M. Carrier erythrocytes: recent advances, present status, current trends and future horizons. Expert Opin Drug Deliv. 2014;11(3):433-447.

42. Hu CM, Fang RH, Zhang L. Erythrocyte-inspired delivery systems. Adv Healthc Mater. 2012;1(5):537-547.

43. Bhateria M, Rachumallu R, Singh R, Bhatta RS. Erythrocytes-based synthetic delivery systems: transition from conventional to novel engineering strategies. Expert Opin Drug Deliv. 2014;11(8):1219-1236.

44. Favretto ME, Cluitmans JC, Bosman GJ, Brock R. Human erythrocytes as drug carriers: loading efficiency and side effects of hypotonic dialysis, chlorpromazine treatment and fusion with liposomes. J Control Release. 2013;170(3):343-351.

45. Mukthavaram R, Shi G, Kesari S, Simberg D. Targeting and depletion of circulating leukocytes and cancer cells by lipophilic antibody-modified erythrocytes. J Control Release. 2014;183:146-153.

46. Zhou Y, Yang B, Ren X, et al. Hyperbranched cationic amylopectin derivatives for gene delivery. Biomaterials. 2012;33(18):4731-4740.

47. Mukherjee R, Chaudhury K, Chakraborty C. Topological features of erythrocytes in thalassemic patients: quantitative characterization by scanning electron and atomic force microscopy. Anal Quant Cytopathol Histpathol. 2014;36(2):91-99.

48. Yin JJ, Sharma S, Shumyak SP, et al. Synthesis and biological evaluation of novel folic acid receptor-targeted, $\beta$-cyclodextrin-based drug complexes for cancer treatment. PLoS One. 2013;8(5):e62289.

49. Li YC, He SM, He ZX, et al. Plumbagin induces apoptotic and autophagic cell death through inhibition of the PI3K/Akt/mTOR pathway in human non-small cell lung cancer cells. Cancer Lett. 2014;344(2):239-259.

50. Rowe GE, Welch RA. Assays of hemolytic toxins. Methods Enzymol. 1994;235:657-667.

51. [No authors listed]. Standard recommended practice for the assessment of the hemolytic properties of materials. Artif Organs. 1978;2(3): 318-320.

52. Wu Y, Hu Y, Cai J, et al. Time-dependent surface adhesive force and morphology of RBC measured by AFM. Micron. 2009;40(3):359-364.

53. Smith MJ, Brown JM, Zamboni WC, Walker NJ. From immunotoxicity to nanotherapy: the effects of nanomaterials on the immune system. Toxicol Sci. 2014;138(2):249-255. 
54. Elsabahy M, Wooley KL. Cytokines as biomarkers of nanoparticle immunotoxicity. Chem Soc Rev. 2013;42(12):5552-5576.

55. Zhang M, Jin J, Chang YN, Chang X, Xing G. Toxicological properties of nanomaterials. J Nanosci Nanotechnol. 2014;14(1):717-729.

56. Sarkar A, Ghosh M, Sil PC. Nanotoxicity: oxidative stress mediated toxicity of metal and metal oxide nanoparticles. J Nanosci Nanotechnol. 2014;14(1):730-743

57. Wang S, Li Y, Fan J, et al. The role of autophagy in the neurotoxicity of cationic PAMAM dendrimers. Biomaterials. 2014;35(26): $7588-7597$.

58. Xu L, Zhang H, Wu Y. Dendrimer advances for the central nervous system delivery of therapeutics. ACS Chem Neurosci. 2014;5(1):2-13.

59. Sadekar S, Ghandehari H. Transepithelial transport and toxicity of PAMAM dendrimers: implications for oral drug delivery. Adv Drug Deliv Rev. 2012;64(6):571-588.

60. Shen W, van Dongen MA, Han Y, et al. The role of caveolin-1 and syndecan-4 in the internalization of PEGylated PAMAM dendrimer polyplexes into myoblast and hepatic cells. Eur J Pharm Biopharm. 2014; 88(3):658-663.

61. Barua S, Mitragotri S. Challenges associated with penetration of nanoparticles across cell and tissue barriers: a review of current status and future prospects. Nano Today. 2014;9(2):223-243.

62. Ziemba B, Matuszko G, Bryszewska M, Klajnert B. Influence of dendrimers on red blood cells. Cell Mol Biol Lett. 2012;17(1):21-35.

63. Dumez H, Reinhart WH, Guetens G, de Bruijn EA. Human red blood cells: rheological aspects, uptake, and release of cytotoxic drugs. Crit Rev Clin Lab Sci. 2004;41(2):159-188.

64. Svetina S. Red blood cell shape and deformability in the context of the functional evolution of its membrane structure. Cell Mol Biol Lett. 2012;17(2):171-181.

65. Ford J. Red blood cell morphology. Int J Lab Hematol. 2013;35(3): 351-357.

66. Diez-Silva M, Dao M, Han J, Lim CT, Suresh S. Shape and biomechanical characteristics of human red blood cells in health and disease. MRS Bull. 2010;35(5):382-388.

67. Wrobel D, Kolanowska K, Gajek A, et al. Interaction of cationic carbosilane dendrimers and their complexes with siRNA with erythrocytes and red blood cell ghosts. Biochim Biophys Acta. 2014;1838(3):882-889.

68. Liu KC, Yeo Y. Zwitterionic chitosan-polyamidoamine dendrimer complex nanoparticles as a pH-sensitive drug carrier. Mol Pharm. 2013; 10(5):1695-1704.

69. Wen Y, Yao F, Sun F, et al. Antibacterial action mode of quaternized carboxymethyl chitosan/poly(amidoamine) dendrimer core-shell nanoparticles against Escherichia coli correlated with molecular chain conformation. Mater Sci Eng C Mater Biol Appl. 2015;48:220-227.

70. Wang M, Hu H, Sun Y, et al. A pH-sensitive gene delivery system based on folic acid-PEG-chitosan - PAMAM-plasmid DNA complexes for cancer cell targeting. Biomaterials. 2013;34(38):10120-10132.
71. Han MH, Chen J, Wang J, Chen SL, Wang XT. Blood compatibility of polyamidoamine dendrimers and erythrocyte protection. J Biomed Nanotechnol. 2010;6(1):82-92.

72. Smith PE, Brender JR, Dürr UH, et al. Solid-state NMR reveals the hydrophobic-core location of poly(amidoamine) dendrimers in biomembranes. J Am Chem Soc. 2010;132(23):8087-8097.

73. Kelly CV, Liroff MG, Triplett LD, et al. Stoichiometry and structure of poly(amidoamine) dendrimer-lipid complexes. ACS Nano. 2009;3(7): 1886-1896.

74. Parimi S, Barnes TJ, Prestidge CA. PAMAM dendrimer interactions with supported lipid bilayers: a kinetic and mechanistic investigation. Langmuir. 2008;24(23):13532-13539.

75. Yan LT, Yu X. Enhanced permeability of charged dendrimers across tense lipid bilayer membranes. ACS Nano. 2009;3(8):2171-2176.

76. Hong S, Leroueil PR, Janus EK, et al. Interaction of polycationic polymers with supported lipid bilayers and cells: nanoscale hole formation and enhanced membrane permeability. Bioconjug Chem. 2006;17(3): $728-734$.

77. Greish K, Thiagarajan G, Herd H, et al. Size and surface charge significantly influence the toxicity of silica and dendritic nanoparticles. Nanotoxicology. 2012;6(7):713-723.

78. Zhang X, Zhao J, Wen Y, Zhu C, Yang J, Yao F. Carboxymethyl chitosanpoly(amidoamine) dendrimer core-shell nanoparticles for intracellular lysozyme delivery. Carbohydr Polym. 2013;98(2):1326-1334.

79. Leng ZH, Zhuang QF, Li YC, et al. Polyamidoamine dendrimer conjugated chitosan nanoparticles for the delivery of methotrexate. Carbohydr Polym. 2013;98(1):1173-1178.

80. Kim TI, Bai CZ, Nam K, Park JS. Comparison between arginine conjugated PAMAM dendrimers with structural diversity for gene delivery systems. J Control Release. 2009;136(2):132-139.

81. Wang L, Wang Z, Ma G, Lin W, Chen S. Reducing the cytotoxity of poly(amidoamine) dendrimers by modification of a single layer of carboxybetaine. Langmuir. 2013;29(28):8914-8921.

82. Kavosi B, Salimi A, Hallaj R, Amani K. A highly sensitive prostatespecific antigen immunosensor based on gold nanoparticles/PAMAM dendrimer loaded on MWCNTS/chitosan/ionic liquid nanocomposite. Biosens Bioelectron. 2014;52:20-28.

83. Liu X, Ma D, Tang H, et al. Polyamidoamine dendrimer and oleic acidfunctionalized graphene as biocompatible and efficient gene delivery vectors. ACS Appl Mater Interfaces. 2014;6(11):8173-8183.

84. Triulzi RC, Micic M, Giordani S, Serry M, Chiou WA, Leblanc RM. Immunoasssay based on the antibody-conjugated PAMAMdendrimer-gold quantum dot complex. Chem Commun. 2006;48: 5068-5070.

85. Triulzi RC, Micic M, Orbulescu J, Giordani S, Mueller B, Leblanc RM. Antibody-gold quantum dot-PAMAM dendrimer complex as an immunoglobulin immunoassay. Analyst. 2008;133(5):667-672.
Drug Design, Development and Therapy

\section{Publish your work in this journal}

Drug Design, Development and Therapy is an international, peerreviewed open-access journal that spans the spectrum of drug design and development through to clinical applications. Clinical outcomes, patient safety, and programs for the development and effective, safe, and sustained use of medicines are a feature of the journal, which

\section{Dovepress}

has also been accepted for indexing on PubMed Central. The manuscript management system is completely online and includes a very quick and fair peer-review system, which is all easy to use. Visit http://www.dovepress.com/testimonials.php to read real quotes from published authors. 